\title{
Bleeding Meckel's in Pregnancy: A Rare Cause of a Rare Phenomenon
}

\author{
Rahul R. Sima ${ }^{1}$, Clement S. Rajan², Srikanth K. Aithal ${ }^{3}$ \\ ${ }^{1}$ Department of Surgery, St. John's Medical College, Bangalore, India \\ ${ }^{2}$ Department of Surgery, Mallya Hospital, Bangalore, India \\ ${ }^{3}$ Department of Surgery, St. Martha's Hospital, Bangalore, India \\ Email: "rahulsima@gmail.com
}

Received 23 January 2016; accepted 22 February 2016; published 25 February 2016

Copyright (C) 2016 by authors and Scientific Research Publishing Inc.

This work is licensed under the Creative Commons Attribution International License (CC BY). http://creativecommons.org/licenses/by/4.0/

(c) (i) Open Access

\section{Abstract}

Meckel's diverticulum complicating pregnancy is indeed a rare occurrence. The anatomical and physiological changes that occur in pregnancy make the clinical presentation and preoperative diagnosis of an acute abdomen extremely difficult. Even imaging modalities have to be used with caution keeping in mind the risks associated for both mother and fetus. Treatment of such cases must be prompt and accurate with a high index of suspicion in order to prevent high rate of maternal and fetal morbidity. We report one such case of bleeding of Meckel's diverticulum. The most common cause of bleeding in a Meckel's is ectopic gastric mucosa. When we performed an exploratory laparotomy we found to our surprise a bleeding Meckel's diverticulum. Further investigations revealed a very interesting histopathological report of endometriosis as the cause of bleed.

\section{Keywords}

Bleeding Meckel's, Meckel's Complicating Pregnancy, Heterotropic Endometrial Tissue

\section{Introduction}

Meckel's diverticulum is a congenital anomaly, remnant of the vitello-intestinal duct which is present in $2 \%$ of population on the antimesenteric border of the small intestine, about $60 \mathrm{~cm}$ from the ileo-cecal junction [1] [2]. $20 \%$ of cases have mucosa with heterotropic epithelium, gastric, colonic or even pancreatic tissue. Equal distribution in both males and females is seen; however symptomatic Meckel's is more in males with hemorrhage due to ulceration of peptic mucosa, intussusceptions and Meckel's diverticulitis, with or without perforation due to obstruction mimicking appendicitis being the common presentations [1] [3].

\footnotetext{
${ }^{*}$ Corresponding author.
} 


\section{Case Report}

A 28 years old lady presented to our hospital in the $24^{\text {th }}$ week of her second pregnancy with non bilious, non blood tinged vomiting 2 - 3 episodes per day for the past week, burning sensation while passing urine for a week, dark coloured stools for 3 days. She also complained of mild, dull aching, non radiating pain in the lower abdomen for a day. Patient had had a previous Caesarean section.

On examination we recorded severe pallor, tachycardia of 110/min, her abdomen was non tender but soft; uterine size corresponded to gestational age. There was no organomegaly or mass, no free fluid. Bowel sounds were decreased and sluggish and a per rectal examination showed a blood stained glove.

Initial laboratory investigations revealed Haemoglobin of 3.7 gm/dl, PCV 11.4\%, Platelet count 1.28 lakhs, total count 17,100 , neutrophils $92 \%$, peripheral smear showed normocytic normochromic picture with moderate neutrophilic-leukocytosis; all other investigations including liver function test and urine routine were normal. Colonoscopy reported blood and altered blood coating the mucosa with no obvious colonic pathology, a suggestion to rule out small bowel bleed was made (Figure 1). Upper GI endoscopy was normal.

Patient was admitted to the surgical intensive care, stabilised and she received blood and fresh frozen plasma transfusions. Patient continued to have melena and blood in stools. Mesenteric Angiogram was done and this gave a probable diagnosis of a Gastro intestinal stromal tumor in the ileum with the evidence of bleed (Figure 2). Patient continued to bleed and deteriorate and hence was taken up for emergency laprotomy.

A Meckel's diverticulum with wide based mass within probably gastric mucosa was seen.

Bowel distal to Meckel's was loaded with altered blood. Rest of the bowel and abdomen was normal (Figure 3). A resection and single layered end to end anastamosis was performed. The patient had a normal, uneventful post-operative recovery and was discharged. During the entire process fetal heart rate was regularly monitored by Doppler.

At term, patient delivered a healthy baby by C-section.

The histopathological report showed Meckel's diverticulum, partly lined by intestinal mucosa, with an area of ulceration covered by fibrin, acute inflammatory cells and granulation tissue. The wall of the Meckel's diverticulum showed a patch of endometrial tissue showing decidual change (Figure 4). The impression being Meckel's diverticulum showing ulceration and endometriosis with decidual change.

\section{Discussion}

Meckel's diverticulum complicating pregnancy is an extremely rare entity with hemorrhage being the most common complication [4]. Other complications of Meckel's diverticulum in the form of diverticulitis and

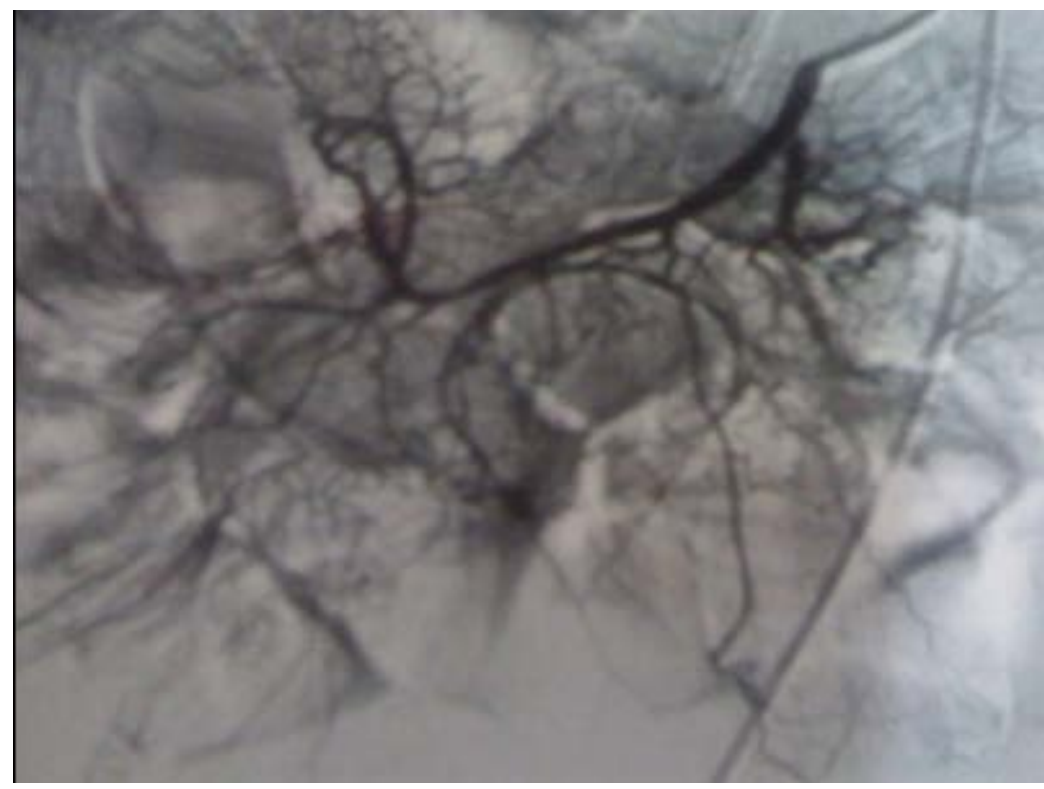

Figure 1. Mesentric angiogram showing GIST with arterial blush. 


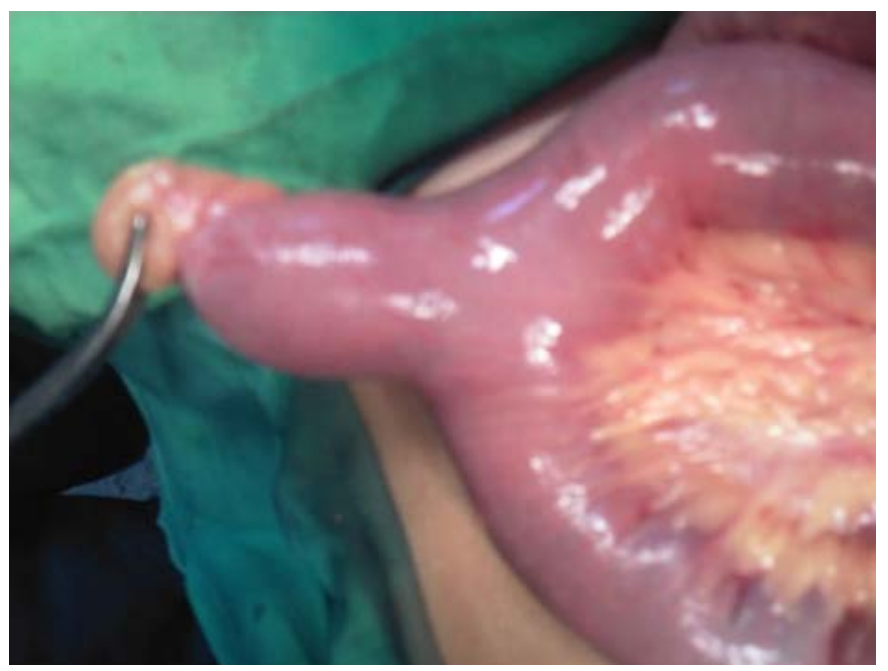

Figure 2. Intra-operative finding Meckel’s diverticulum, with distal bowel distended with blood.

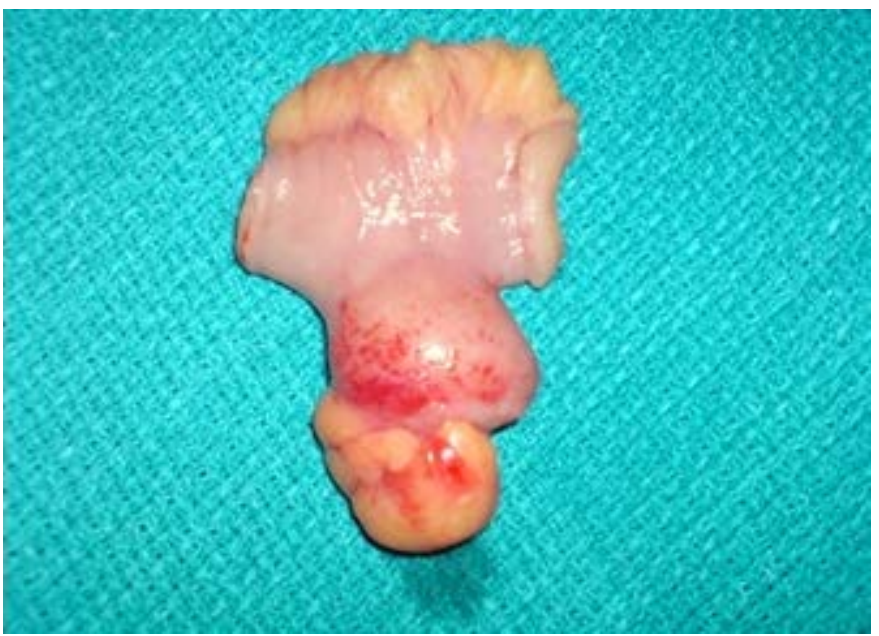

Figure 3. Resected operated specimen.

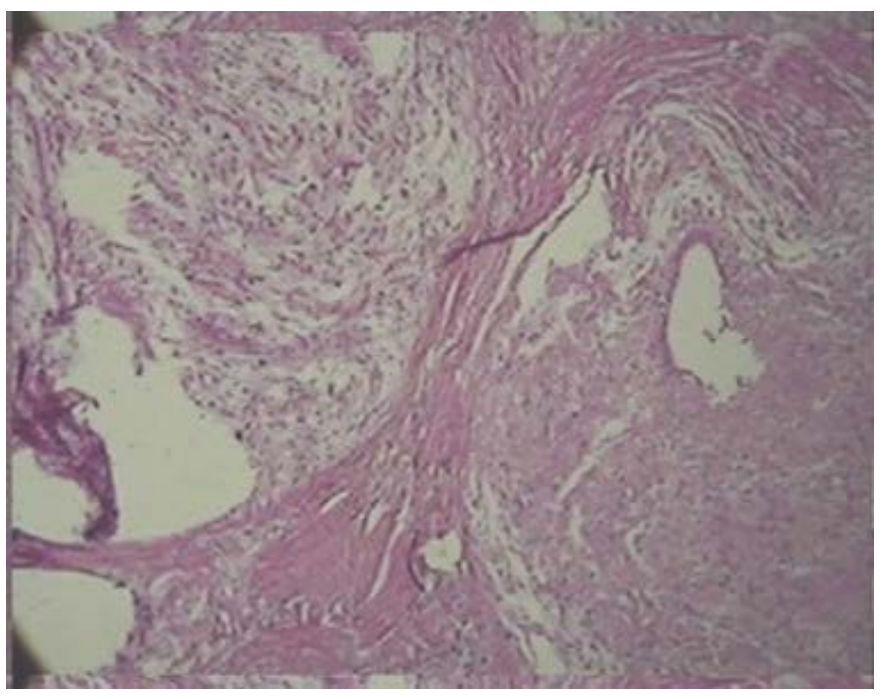

Figure 4. High Power view showing endometrial tissue with decidual changes in Meckel’s diverticulum $(H \& E \times 40)$. 
obstruction and perforation have also been reported [5]-[7]. One of the major causes of emergency hospital visits in adults is gastrointestinal bleeding. $80 \%$ of the bleeding in adults is from the upper gastrointestinal tract. The most common source of the lower gastrointestinal bleeding is colon, with less than $5 \%$ of bleeding from small intestine [8]. Investigations include upper gastrointestinal endoscopy and colonoscopy as well as biochemical and haematological investigations. Endoscopy may not be useful when visibility is obscured due to pooling of blood. Technetium-bleeding scan and angiography may be used to diagnose rare focal sources of bleeding such as Meckel's diverticulum.

Meckel's diverticulum is lined mainly by the typical ileal mucosa as in the adjacent small bowel. However, ectopic gastric (most common—57\% according to textbooks, but 20\% according to recent data [9])—duodenal, colonic, pancreatic, Brunner's glands, hepatobiliary tissue and endometrial mucosa may be found, usually near the tip [8].

In the English literature, Klinvimol et al. reported that out of 1489 patients only $0.27 \%$ of the patients had bleeding [10] [11], while Leijonmarck et al. recorded only 5\% of patients out of 260 having bleeding [12].

In the literature, there were only 24 cases reported since 1949. Endometriosis in Meckel's diverticulum is a rare entity and we did not find any literature on endometriosis (heteroptopic) being reported in a Meckel's diverticulum. Hence this case is an unique report of a rare case of bleeding Meckel's diverticulum in pregnancy.

\section{Conclusion}

Lower gastrointestinal bleed during pregnancy can be a life threatening emergency, where imaging and diagnostic modalities are often restricted. A systematic approach to diagnosis and surgery when indicated is the best therapeutic option. Meckel's diverticulum complication pregnancy can be treated successfully with surgery.

\section{References}

[1] Cullen, J.J., Kelly, A.K., Moir, C.R., et al. (1994) Surgical Management of Meckel’s Diverticulum and Epidemiologic, Population-Based Study. Annals of Surgery, 4, 564-569. http://dx.doi.org/10.1097/00000658-199410000-00014

[2] Bemelman, W.A., Hugenholtz, E., Heiji, H.A., Wiersma, P.H. and Obertop, H. (1995) Meckel's Diverticulum in Amsterdam: Experience in 136 Patients. World Journal of Surgery, 19, 734-737. http://dx.doi.org/10.1007/BF00295917

[3] Michas, C.A., Cohen, S.E. and Wolfman Jr., E.F. (1975) Meckel’s Diverticulum: Should It Be Excised Incidentally at Operation? American Journal of Surgery, 129, 682-685. http://dx.doi.org/10.1016/0002-9610(75)90345-1

[4] St-Vil, D., Brandt, M.L., Panic, S., Bensoussan, A.L. and Blanchard, H. (1991) Meckel’s Diverticulum in Children: A 20-Year Review. Journal of Pediatric Surgery, 26, 1289-1292. http://dx.doi.org/10.1016/0022-3468(91)90601-O

[5] Rudloff, U., Jobanputra, S., Smith-Levitin, M. and Kesser, E. (2005) Meckel’s Diverticulum Complicating Pregnancy: Case Report and Review of Literature. Archives of Gynecology and Obstetrics, 271, 89-93. http://dx.doi.org/10.1007/s00404-004-0641-y

[6] Huerta, S., Barleben, A., Peck, M.A. and Gordon, I.L. (2006) Meckel’s Diverticulitis: A Rare Eitiology of an Acute Abdomen during Pregnancy. Cur Surgical, 63, 290-293. http://dx.doi.org/10.1016/j.cursur.2006.02.009

[7] Wong, Y.S., Liu, S.Y.W., Ng, S.S.M., et al. (2010) Giant Meckel’s Diverticulitis: A Rare Condition Complicating Pregnancy. American Journal of Surgery, 200, 184-185. http://dx.doi.org/10.1016/j.amjsurg.2009.10.019

[8] Stone, P.A., Hofeldt, M.J., Lohan, J.A., Kessel, J.W. and Flaherty, S.K. (2005) A Rare Case of Massive Gastrointestinal Hemorrhage Caused by Meckel’s Diverticulum in a 53-Year-Old Man. West Virginia Medical Journal, 101, 64-66.

[9] Cserni, G. (1996) Gastric Pathology in Meckel’s Diverticulum. Review of Cases Resected between 1965 and 1995. American Journal of Clinical Pathology, 106, 782-785.

[10] Andreyev, H.J., Owen, R.A., Thompson, I. and Forbes, A. (1994) Association between Meckel's Diverticulum and Crohn's Disease: A Retrospective Review. Gut, 35, 788-790. http://dx.doi.org/10.1136/gut.35.6.788

[11] Klinvimol, T., Ho, Y.H., Parry, B.R. and Goh, H.S. (1994) Small Bowel Causes of per Rectum Hemorrhage. Annals Academy of Medicine Singapore, 23, 866-888.

[12] Leijonmarck, C.E., Bonman-Sandelin, K., Frisell, J. and Raf, L. (1986) Meckel’s Diverticulum in the Adult. British Journal of Surgery, 73, 146-149. http://dx.doi.org/10.1002/bjs.1800730225 